\title{
VIENDO EL SENTIDO: SIMILITUDES Y JUEGOS SÍGNICOS EN MAGRITTE
}

\author{
SEEING THE SENSE: SIMILIARITIES AND GAMES OF SIGNS \\ IN MAGRITTE
}

Saleta DE SALVADOR AGRA

Universidade de Vigo

saleta@uvigo.es

Resumen: La pintura de Magritte, calificada como una forma de hacer visible lo invisible, se presenta como un lugar desde el cual re-pensar los juegos de la representación, de la percepción, de la interpretación y del funcionamiento del sentido. La concepción sígnica subyacente a sus cuadros nos permitirá poner en primer plano la crítica al concepto de semejanza representativa, en un recorrido que va desde Peirce, pasando por Eco, hasta la propuesta de similitud anunciada por el propio Magritte y ampliada por Foucault. El objetivo del texto es, por tanto, reinterpretar conceptos asentados en la teoría semiótica a la luz de las textualidades magritteanas con el fin de acercarnos al proceso de "ver el sentido" que nos propone el pintor.

Palabras clave: similitud, semejanza icónica, semiosis, Foucault, Peirce.

Abstract: Magritte's pictures, described as a form of invisible visibility, is presented as a place from which to re-think the representation, perception, interpretation and meaning games. The signic conception underlying 
his pictures carry to the foreground the criticism to the concept of representative resemblance, in a project that goes from Peirce, through Eco, to the proposal of similitude announced by Magritte and enlarged by Foucault. The aim of this text is, therefore, to reinterpret the established concepts of semiotic theory in light of magrittean textualities in order to approach us to the process of "see the sense" that the painter proposes to us.

Key Words: similitude, iconic resemblance, semiosis, Foucault, Peirce.

\section{LO VISIBLE, LO INVISIBLE Y OTRAS FORMAS DE NO- VISIÓN}

La pintura de René François Ghislain Magritte se ha calificado como una forma de hacer visible el pensamiento -lo invisible-, lo cual se podría interpretar así porque estimula de una manera excepcional a pensar, a cuestionar la fragilidad de la convencionalidad del lenguaje, a dejarse sorprender mientras se aprecian sus desconcertantes imágenes, pero fundamentalmente porque, como él mismo dejó escrito, "una imagen pintada no representa ideas o sentimientos, sino que son los sentimientos o las ideas las que pueden representar la imagen pintada" (Magritte, cit. en Fernández Taviel de Andrade, 2000: 19). Es quien mira, para Magritte, quien representa el cuadro, quien proyecta sus ideas y sentimientos en el mismo $^{1}$; lo invisible sobre lo visible, el significado sobre el significante.

El punto de inflexión otorgado al destinatario -en clara consonancia con el arte como apertura propugnado por Umberto Eco (2009)- sitúa a éste en el centro, en una participación activa, no contemplativa, frente a la obra que sirve como pretexto para asociar e interpretar lo visto, para desvelar lo invisible. En una entrevista, recogida en el documental fílmico de Adrian Maben, Monsieur René Magritte de 1978, el pintor afirmaba que

1. Esto podría conducir a interpretar las reflexiones de Magritte como un tipo de subjetivismo, donde todo está en la mirada del sujeto -el conocimiento dependiente de él- y no en el objeto. Es lo que él denominó primeramente como "extramentalismo" y después como "amentalismo", el cual teorizó en su "Manifeste de 1'Amentalisme" de 1946, donde postuló y desarrolló sus tres premisas básicas, a saber; 1) "todo ocurre en nuestro universo mental", 2) "no nos es posible tener cualquier cosa, excepto tener el universo mental" y, por último, 3) "la noción de la existencia de lo amental es la única que podemos tener sobre el tema de lo amental" (Magritte, 2003: 195-196). 
"todo lo visible oculta algo que no se ve", remitiéndonos así a su central preocupación por el misterio, por lo incognoscible, por lo ausente que está presente en lo visible, por lo invisible. Al colocar imágenes de objetos cotidianos en situaciones inauditas (un huevo gigante en una jaula, una rosa descomunal aprisionada en una habitación, una gigante roca flotando en el aire, una planta de la que brotan pájaros-hojas, cuerpos y rostros cubiertos por telas, etc.), el pintor logra provocar un efecto asombroso y turbador en el espectador. Éste, según Magritte, deberá tener la "sensibilidad de un turista" al acercarse a sus pinturas, deberá dejarse sorprender, como un niño, ante la extrañeza de imágenes de cosas familiares, observarlas como si fuera la primera vez que se hace. Así, afirma que "en lugar de sorprenderse por la existencia superflua de otro mundo, es nuestro único mundo en el que las coincidencias nos sorprenden, el que es necesario no perder de vista" (Magritte, 2003: 327). Convierte de este modo al arte en un dispositivo de desvelamiento y a nuestro mundo en un misterio (Sampedro, 1993). En una carta dirigida a Jean Wahl, del 3 de febrero de 1967, Magritte dejaba escrito: “yo me 'ocupo' de la pintura para evocar, con imágenes desconocidas, lo que es conocido, el misterio de lo absoluto del visible y de lo invisible..." (Magritte, 2003: 295). Son, por tanto, los juegos de la visibilidad los que plasma en sus pinturas: "la descripción visible (una imagen pintada) de un pensamiento invisible (constituido por las figuras visibles unidas en cierto orden) es de 'imposible posible' o, en otros términos, de "lo invisible visible"” (Magritte, 2003: 280).

Aunque, como sostuvo el propio Magritte, respecto de la tela de la pintura, las palabras y las imágenes están hechas de la misma sustancia ${ }^{2}$, pese a ello, podríamos preguntarnos, si es cierto que la imagen visibiliza lo ausente, ¿qué ocurre con la palabra?, “¿no es quizás aquella que siendo ella misma indica algo distinto de sí, aquello que en la simulación de una presencia muestra la ausencia de la cosa representada?" (Casetti, 1980: 106). Expresado con Emilio Lledó: "La visión de la palabra es una forma peculiar de visión. Con la palabra se ve lo no-visto, o incluso, lo no visible" (Lledó, 1991: 69). La palabra vehicula y representa entonces algo diferente

2. A este propósito escribe, en 1929, en Les mots et les images debajo del siguiente dibujo:

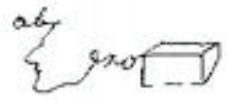

"Dans un tableau, les mots sont de la même substance que les images". 
de sí misma, nos lleva hacia algo distinto de ella. Es, se podría decir, extraña a sí misma pues hospeda la otredad, incorpora la alteridad. La palabra alude a lo no presente convocando la diferencia. El realismo mágico de Magritte ejemplifica justamente este poder que tienen las palabras. En 1927 pintaba la serie titulada L'usage de la parole, L'Espoir rapide y, un año más tarde, Le Miroir vivant de la que existen varias versiones como Le masque vide o los posteriores óleos Miroir magique y L'arbe de la science, en la misma línea. En todos estos cuadros no existe ninguna representación pictórica realista, o pseudo-realista, una presupuesta fidelidad figurativa y supuestamente análoga con el modelo que tanto ha caracterizado a sus obras, sino que únicamente hay palabras sin imágenes.

Por ejemplo, en el caso concreto de Le Miroir vivant, sobre un fondo oscuro, las palabras desplazan al objeto al que refieren, sustituyendo el signo lingüístico al pictórico. Las palabras, situadas dentro de círculos amorfos, en el interior de una especie de nubes conectadas, actúan a modo de un "espejo viviente" que nada más que refleja lo que nosotros queremos ver. Un espejo donde, al igual que en Miroir magique, no se devuelve la mirada de la realidad sino del pensamiento, donde las letras escritas adquieren distintas resonancias dependiendo de quien las lea, de su uso, como bien sugiere el título que da nombre a toda la serie: L'usage de la parole. Dándole forma al deforme círculo que las rodea, Magritte consigue recordarnos nuestra capacidad de producir imágenes, de producir el mensaje desde la instancia de recepción (Eco, 2012). Esto es, la pasividad del espejo frente a la actividad del que mira, pues "el espejo no interpreta. Pero, y esto es decisivo, nosotros interpretamos el espejo" (Konersmann, 1996: 44). De este modo, el pintor, tan sólo con palabras (horizont, armoire, personage èclatant de rire, cris d'oiseaux o fusil, nuage, cheval, chaussée, corps humain), nos señala cómo se presenta lo ausente a través de ellas, cómo el lenguaje alude a las cosas mostrando lo no-visto.

Conjugando ambos lenguajes, el pictórico y el escrito, en La clé des songes $^{3}$ (1930), el surrealista belga nos ofrece el proceso de la significación, su funcionamiento, y su juego de la representación. Allí, llamándole luna a la imagen de un zapato, nieve a la de un sombrero, tormenta a la de un vaso, acacia a la de un huevo, techo a la imagen de una vela o desierto

3. Este mismo cuadro de Magritte le sirve al crítico John Berger (2000) para insistir en su tesis de la separación entre la palabra y lo visto. 
a la de un martillo, consigue visibilizar la idea saussureana de que el signo es arbitrario, de que no existe una relación indisoluble, natural, entre el lazo que une el significante, "imagen acústica", al significado, "imagen mental". Debido a la convención que establece ciertas asociaciones, que unen el nombre y la cosa, la sensación de perplejidad se hace presente. Las textualidades magritteanas plasman entonces, de forma gráfica, cómo los mismos signos sustituyen "la ausencia de lo que falta con una presencia diversa” (Casetti, 1980: 130). Ya que, como bien apuntó el filósofo François Récanati (1979), los signos responden a la doble lógica de la transparencia y la opacidad ${ }^{4}$, de la presencia y de la ausencia, de la visibilidad y la invisibilidad: "Decir que el signo debe estar presente y ausente a la vez, para poder desempeñar su función, es decir que oscila entre la transparencia y la opacidad, estando su capacidad representativa irreductiblemente ligada a esta oscilación" (Récanati, 1981: 17).

\section{CECI ESTUNSIGNE: ENTRE LOVISIBLE Y LO INVISIBLE}

En Clairvoyance (1936), René Magritte se autorretrata en su labor de pintor. Sentado frente a un taburete, lo podemos apreciar de espaldas dibujando un pájaro volando, con las alas abiertas, mientras el pintor mira hacia un huevo situado en una mesa. Así, de un modo, clarividente, nos muestra cómo la pintura no es una reproducción o imitación pasiva de la realidad", pues "entre las imágenes y las cosas se abre un vacío que tampoco el arte permite cerrar" (Konersmann, 1996: 18). La persona que pinta provoca con el pincel la distancia que separa la imagen de aquello que busca representar, esto es, el salto del pájaro al huevo que presenta Magritte. En ese trecho entre uno y otro, en esa distancia entre la imagenpájaro y su referente-huevo, entre las imágenes, las palabras, y las cosas, surge su reveladora capacidad: el poder de re-presentar la ausencia que albergan los signos en tanto sustitutos, y su capacidad para ser usados para mentir, para traicionar 6 , ya que, como nos enseñó Umberto Eco, "si una

4. Este doble sentido del signo propuesto por Récanati, en tanto presentado como una "teoría ingenua", es completado por una "teoría elaborada" que no podremos tomar en cuenta puesto que nos alejaría considerablemente de nuestro tema. Remito, por tanto, a su texto La transparence et l'enunciation. Pour introduire à la pragmatique (1979) para una mayor profundización.

5. Crítica dirigida a la teoría mimética como mera copia. La realidad no es reproducida sino representada.

6. Magritte defendía que sus títulos no eran aclaraciones de su pintura, no eran explicativos sino que 
cosa no puede usarse para mentir, en ese caso tampoco puede usarse para decir la verdad: en realidad, no puede usarse para decir nada" (Eco, 1977: 31). Magritte consigue así de una forma clara, intuitiva, sutil, perspicaz -en definitiva- clarividente, mostrarnos justamente la potencialidad del mundo sígnico y, concretamente, el poder de los signos de ser usados para mentir gracias a mostrar y a jugar con la distancia existente entre el huevo y el pájaro, entre las imágenes y las cosas.

Ceci n'est pas une pipe, Ceci n'est pas une pomme escribía René Magritte en dos de sus cuadros más célebres. No es ni una pipa ni una manzana, afirmaba, pues, si por el contrario lo fuera -nos reta el pintor¿seríamos capaces de rellenar la pipa de tabaco? o de ¿saborear la manzana? Si debajo hubiera escrito "Esto es una pipa" estaríamos ante una mentira, como él mismo nos advierte. Pintar una pipa, representarla, no es la pipa 'real' porque ni la imagen, ni tan siquiera las palabras, garantizan la existencia en la realidad de tal objeto representado. Es decir, no es una pipa ni una manzana sino un signo:

La manzana, aunque se la pinte de manera que llegue a despertar el apetito, no es más que color sobre una superficie preparada. Pero tampoco la palabra «manzana» es la fruta misma, sino -tal como su imagen- una mera designación en el fondo arbitraria (Magritte, cit. en Paquet, 2000: 9).

En esta declaración magritteana se esconde aquella vieja y clásica controversia: la perdurable cuestión problemática sobre la correlación entre el lenguaje y la realidad. La teorización de la génesis de tal relación es tan extensa que llevaría a remontarse a la Grecia Arcaica. En Los trabajos y los días, Hesíodo ya establecía la distinción clave entre signo natural, signo divino y signo convencional (Calabrese, 2001). Se destapaba la caja de los truenos de Pandora, iniciándose, de este modo, el suntuoso y largo camino sobre el carácter convencional o no del lenguaje, que recorre y atraviesa

su pretensión era buscar con ellos acentuar la arbitrariedad de la propia nominación, jugar y perturbar. Así, dejó escrito: "Elijo los títulos de tal forma que impidan situar mis cuadros en una región familiar que encontraría el desarrollo automático del pensamiento con el fin de no inquietarse" (Magritte, 2003: 87). Sin embargo cabe destacar que los escogidos para el cuadro de la pipa fueron significativamente el de La traición de las imágenes (1928/1929) y El uso idiomático (1928/1929). 
la propia historia de la filosofía. Precisamente ésta fue la cuestión central del Crátilo de Platón. El diálogo entre Hermógenes, Sócrates y Crátilo recoge el sentir de las dos posturas básicas en torno a aquella contienda. Por un lado, la convencionalista, hija de los eleatas y sofistas, capitaneada por Hermógenes, y, por el otro lado, la naturalista, inspirada en Heráclito y en los cínicos, en especial en Antístenes, argumentada por el filósofo ateniense Crátilo. En líneas generales, el debate entre los interlocutores, inserto en la dualidad nomoi-physis, postulaba el carácter funcional y social de los signos (las palabras se relacionan por acuerdo o ley con las cosas) frente a concebirlos como duplicados de las cosas existentes (las palabras se vinculan de forma natural con las cosas).

En los dos cuadros apenas mencionados -La traición de las imágenes (1929) y Esto no es una manzana (1956)- el pintor belga reproduce el conflicto respecto, en ese caso, a los signos icónicos, sugiriendo una reflexión en torno al vínculo que se establece entre lo materialmente presente a los sentidos y lo designado: ¿es fruto de una regulación cultural o simplemente reproducen, copian, el objeto por el que están?, ¿es por ley o por naturaleza que la imagen de la pipa, o de una manzana, remite a una pipa o manzana? Situándose en un enfoque controvertido respecto al marco convencionalista, el artista, en tanto y cuanto hace uso de la propia convención para ponerla en crisis, consigue, en muchas de sus imágenes pictóricas, mostrar y cuestionar la estipulada relación entre el lenguaje y las cosas, criticando la idea de que el lenguaje (la imagen) reenvía a la cosa como un dedo índice, a la vez que muestra la posibilidad de que los signos sean utilizados para mentir, para traicionar.

$\mathrm{Ni}$ tan siquiera el arte más hiperrealista, el cual intenta plasmar o reproducir objetivamente la realidad, se escapa a la convención. Con todo, en estos casos, existe una supuesta semejanza entre el signo y lo representado por él. De acuerdo a la célebre tripartición propuesta por Charles Sanders Peirce, índice, icono y símbolo, que atendía a la relación del signo con el objeto dinámico -identificado con la realidad exterior a la que apunta-, el signo icónico ${ }^{7}$ lo era en virtud de su semejanza con

7. El problema de la iconicidad, vinculado sobre todo a las semióticas visuales, ha llevado al semiólogo Umberto Eco a proponer una nueva taxonomía sígnica frente a la originaria tripartición clásica peirceana de icono, símbolo e índice, esto es, una "tipología de los modos de producción sígnica" (Eco, 1977). La reflexión sobre el iconismo, que germina bajo el concepto de mímesis griega ha dado lugar a variadas discusiones en el seno de la semiótica. Para un recorrido sobre el amplísimo debate del iconismo a partir de Peirce, véase, por ejemplo, en el panorama italiano entre otros; "Il problema dell'iconismo" (Calabrese, 1985), "Appunti 
el objeto designado. Por tanto, algo es "un icono de alguna otra cosa, en la medida en que es como esa cosa y en que es usada como signo de ella" (Peirce 5.247). El "ser como", la cierta semejanza que provoca el icono, tal y como sostuvo Eco, no quiere decir que las imágenes tengan las mismas propiedades físicas que los objetos reales (las cosas) por los que están ${ }^{8}$-el retrato bidimensional de la famosa pipa de Magritte no posee las propiedades de la pipa, ni siquiera en su versión de 1926 pintada en bajo relieve con su impresión de plasticidad- sino que nada más que estimularían una "estructura perceptiva semejante" a la que produciría el objeto (Eco, 1975). El propio Peirce introduce esta idea cuando matiza que "un signo puede ser icónico, es decir, puede representar a su objeto predominantemente por su semejanza (similarity), sin importar cuál sea su modo de ser" y prosigue que "cualquier imagen material, tal como un cuadro de un pintor, es ampliamente convencional en su modo de representación" (Peirce 2.276). Por ende, detrás de la semejanza hay una regulación cultural que hará comprensible el signo, unas reglas de codificación convencionales relativas y no una relación puramente natural. Es, pues, la cultura quien regula, es ella nuestro modo de adaptarnos al medio y quien nos convierte, conforme ha expresado el filósofo neokantiano Ernest Cassirer, en animales simbólicos al enfrentarnos con la realidad no de un modo inmediato, sino mediante la interposición de ese medio artificial que son los signos, el lenguaje.

\section{DE LA SEMEJANZA REPRESENTATIVA AL JUEGO DE LAS SIMILITUDES VISUALES}

El criterio de semejanza, entonces, requiere "cierto adiestramiento" cultural previo, precisa estar regido por reglas que concuerden cuáles son los aspectos del objeto pertinentes o no para la semejanza. Esto está en estrecha relación con la "falacia referencial"" de Eco, ya que para él "una

sull'iconicità" (Maldonado, 2007) o "Iconismo e ipoicone" (Eco, 1997).

8. Interpretación que, de acuerdo con Eco, se debe a una discutida relectura hecha por Charles Morris de los textos de Peirce. Del mismo modo, Deladalle (1996) apuntó a la lectura conductista que Morris hace de Peirce. Recordemos que la definición proporcionada por Morris de icono fue un signo que muestra "en sí mismo las propiedades que un objeto debe tener para ser denotado por él" (Morris, 1985: 59).

9. Cabe recordar que en este razonamiento falaz se incurre cuando la teoría de los códigos, ocupada de la intensión, se contamina con el problema de la referencia, o lo que es lo mismo, el antirreferencialismo de Umberto Eco no concierne a su teoría de la producción de signos, que sí se ocuparía del tema de la extensionalidad, de la posibilidad de usar los signos para referir a cosas. 
expresión no designa un objeto, sino que transmite un contenido cultural" (Eco, 1977: 121). Esto es, a lo que el signo remite no tiene la materialidad física ni la perceptibilidad propia del significante, que siempre es algo que se puede percibir físicamente. Por ello, Eco califica a ese algo a lo que el signo remite como "unidad cultural", una entidad abstracta, intelectualmente perceptible ${ }^{10}$. Es decir, el signo, en principio, no remite a la cosa-objeto pues "el signo funciona en ausencia de las cosas" (Eco cit. en Pancorbo, 1977: 35).

Por más que el ahora solitario dibujo de la pipa intente asemejarse a esa forma que designa de ordinario la palabra pipa; por más que el texto se extienda por debajo del dibujo con toda la atenta fidelidad de un pie de ilustración en un libro científico: entre ambos no puede pasar ya más que la formulación del divorcio, el enunciado que impugna a la vez el nombre del dibujo y la referencia del texto.

En ninguna parte hay pipa alguna (Foucault, 1981: 42-43).

Michel Foucault escribía esto en su célebre texto sobre Magritte Ceci n'est pas une pipe (1973). Allí mantuvo la tesis de que la semejanza es dependiente de un patrón que jerarquiza las relaciones de correspondencia, pero introdujo una diferencia capital, entre ésta y la similitud, suscitada por una carta, fechada el 23 de mayo de 1966, del pintor surrealista a propósito de su obra Les mots e les choses (1966):

Las palabras Semejanza y Similitud le permiten sugerir con rigor la presencia-absolutamente extraña-del mundo y de nosotros mismos. Sin embargo, creo que estas dos palabras apenas están diferenciadas, y los diccionarios apenas son edificantes en cuanto a lo que las distingue.

Me parece que, por ejemplo, los guisantes entre sí tienen relaciones de similitud, a la vez visibles (su color, su forma, su dimensión) e invisibles (su naturaleza, su sabor,

10. Esto no impide que en ciertos procesos semióticos el signo refiera a entidades concretas, físicamente presentes, como por ejemplo ciertos usos de los nombres propios o los pronombres demostrativos o personales. 
su peso). Lo mismo ocurre con lo falso y lo auténtico, etc. Las «cosas» no tienen entre sí semejanzas, tienen o no similitudes (Magritte cit. en Foucault, 1981: 83).

A raíz de esta sugerencia de Magritte, Foucault matiza y profundiza en la diferenciación entre los conceptos de semejanza y similitud, anunciando que el primero busca y pretende suprimir el trecho que separa las imágenes de las cosas de acuerdo a un código, procurando afirmar la realidad y alimentando una relación de correspondencia entre ambas; frente a ello, la similitud, en cambio, juega en ese espacio, subrayando y acentuando la diferencia, es decir, marcando la distancia que separa las imágenes y las palabras de los objetos-cosas.

Con anterioridad al estilo pictórico de Magritte, para el filósofo francés, pintores como Paul Klee y Wassily Kandinsky ya habían conseguido transgredir los dos principios que rigieron el arte occidental desde el siglo XV al XX. El primer principio establecía una relación de separación y subordinación entre las imágenes (implicaban semejanza) y las palabras (excluían la semejanza) y el segundo principio postulaba una "equivalencia entre el hecho de la semejanza y la afirmación de un lazo representativo" (Foucault, 1981: 49). Klee fue quien quebrantó el primero de los principios al no separar los signos lingüísticos de los plásticos. Y lo hizo por medio de la yuxtaposición, de figuras, imágenes que parecían signos, de palabras. Un ejemplo de esto sería el cuadro del artista titulado Legende vom Nil de 1937. El segundo principio fue abolido con la obra del artista ruso Kandinsky al negar que la imagen afirme o narre la realidad -cualquier cuadro de su etapa abstracta ilustraría la idea del arte como contrario a expresar o reproducir el mundo de acuerdo a un modelo exterior-. Aunque alejado de ambos, del lenguaje modernista de Klee y del arte abstracto de Kandinsky, Magritte fue, para Foucault, quien mejor logró transgredir la semejanza, al visibilizar, mejor que nadie, el hiato entre palabras/imágenes y cosas: "Pintura destinada, más que cualquiera otra, a separar, cuidadosamente, cruelmente, el elemento gráfico del elemento plástico" (Foucault, 1981: 51).

Magritte consiguió gracias a una aparente contradicción - una lectura espontánea que asocie las palabras "Esto no es un pipa" y el dibujo de la pipa- deshacer el círculo del caligrama, que hacía coincidir el discurso o el texto con la representación: "Magritte ha vuelto a abrir la trampa que el 
caligrama había cerrado sobre aquello de lo que hablaba. Pero, de golpe, la cosa misma ha desaparecido" (Foucault, 1981: 41). No media vínculo entre lo legible y lo visible, esto es, entre lo que se dice y lo que se ve, entre el nombrar y el mostrar. En palabras de John Berger, Magritte "[h]izo que los dos lenguajes (el visual y el verbal) se anularan mutuamente" (Berger, 1998: 89). Ambos lenguajes no aseguran la semejanza entre la imagen (visible) y la cosa, ni entre la palabra (enunciable) y la cosa o, dicho de otro modo, no señalan la correspondencia ni la equivalencia. En consecuencia, la cosa desaparece pues la pipa-cosa ya no está. Al romper con la inevitable relación del texto con la imagen -enfatizada por el pronombre demostrativo "Esto" (Ceci)-, de tomar la semejanza por la realidad, Magritte consigue quebrantar la ilusión de creer que la pipa (imagen) es una pipa (objeto). Disociando, fractura los vínculos de la semejanza al emanciparla del original, al independizarla de su referencia. La vinculación entre lo real y la copia, el objeto y la representación, se vuelve, por tanto, débil, no directa. De esta suerte, los juegos visuales de las similitudes pictóricas magritteanas presentan la escisión entre las palabras/imágenes y las cosas. En definitiva, subrayan la diferencia entre la realidad y la representación, proclamando su disociación, su no correspondencia exacta. Dicho con la claridad de las palabras del propio pintor: "la imagen de una pipa no es una pipa" (Magritte, 2003: 375) ya que "en ningún caso la imagen se debe confundir con la cosa representada" (Magritte, 2003: 335). Para Nicole Eveaert-Desmedt, la diferencia entre la semejanza y la similitud se sustenta en que la primera "es del orden de la indistinción" y la segunda "del orden de la distinción" (Everaert-Desmedt, 2000: 100). En consecuencia, entre las imágenes (las palabras) y las cosas solo cabe la distinción, sólo hay similitudes y, tal y como nos advierte Magritte, "conviene señalar que las similitudes y las diferencias no son descubiertas más que como actos del pensamiento" (Magritte, 2003: 335). En conclusión, la relación de similitud es fruto del pensamiento y, volviendo a Peirce, conviene recordar que: "El pensamiento no es más que un tejido de signos. Los objetos de los que se ocupa el pensamiento son signos" (MS 1.334). Por tanto, lejos de una acción de semejanza entre las imágenes y las cosas, en los cuadros de Magritte estamos ante una relación puramente sígnica.

A mi modo de ver, una manera, quizás, de aclarar esta distinción foucaultiana, entre la semejanza y la similitud, podría ser pensar la primera como una estructura arbórea, al ser dependiente de un patrón que establece 
relaciones jerárquicas de correspondencia, ordenando las copias de acuerdo a un patrón original. Frente a esto, el procedimiento del "deshacedor de caligramas", del "cazador de similitudes perdidas" (Almansi, 1981: 12), favorece las relaciones rizomáticas de la similitud: "Lo similar se desarrolla en series que no poseen ni comienzo ni fin, que uno puede recorrer en un sentido o en otro, que no obedecen a ninguna jerarquía, sino que se propagan de pequeñas diferencias en pequeñas diferencias" (Foucault, 1981: 64). Una asociación ajerárquica, con "diferentes medios de Medidas"11, que podría recordar parcialmente, a mi modo de ver, al proceder de lo que más tarde Umberto Eco denominó "enciclopedia" o incluso al más actual término de hipertexto como una red excéntrica no ramificada (de Salvador, 2016). De manera que la diferencia propuesta por Magritte, conceptualizada por Foucault, completa la crítica a la relación de la semejanza icónica peirceana al introducir el concepto de similitud, a la vez que la separa de la semejanza representativa y sitúa en primer plano su crítica al hábito que liga las palabras/imágenes y las cosas. En definitiva, es la "protesta contra la evidencia de lo cotidiano" (Scheneede, 1978: 72), la derrota de lo convencional a manos de la propia convencionalidad, lo que las similitudes visuales del pintor belga evocan como actos del pensamiento.

\section{EL RITMO TRIÁDICO DE LAS SIMILITUDES}

La operación pictórica de Magritte consigue hacer de lo convencional -tanto en imágenes como en palabras- algo enigmático, controvertido, misterioso, desde lo imprevisto de sus extrañas asociaciones, en una clara invitación a problematizar nuestra visión. Es decir, sus disociaciones no sólo revelan la contingencia del significado sino que ponen en jaque los mecanismos de la precepción, de la representación, el problema de la imagen y el de la semejanza. A través de sus cuadros, como indica Guido Almansi en el prólogo de la citada obra de Foucault, Magritte logra explorar "toda la gama de la arbitrariedad (de la imagen, de la nominación, de la

11. En el Prefacio del catálogo de la exposición de Magritte, realizada en Milán en 1962, se recogían las siguientes palabras del pintor, donde vuelve a insistir en la diferenciación entre la semejanza y la similitud: "Se puede comprobar la similitud con diferentes medios de Medida. Sin embargo, no se la debe confundir con la semejanza, pese a la costumbre de juzgar semejantes los guisantes, lo falso y lo auténtico, o también el cielo y su reflejo en un lago, que sólo tienen entre sí más o menos relaciones de similitud" (Magritte cit. en Torczyner, 1978: 223). 
semejanza, de la titulación)" (Almansi, 1981: 13). Revela de ese modo la maquinaria inscrita en la producción del sentido, a la vez que descubre los juegos de la artificialidad, de la convencionalidad, de la arbitrariedad, de la ambigüedad, de la provisionalidad e indeterminación que caracteriza a todo signo.

El signo no es una entidad fija sino provisional y temporal, mutable, "aperta", como sostuvo Eco (2009), abierta ya que su sentido es dependiente de la cultura, tanto respecto del emisor como del receptor, dependiente de una correlación codificadora mutable. Frente a la inmanencia del signo, a un sentido que lo cierre herméticamente, se destaca así el carácter variable como parte constitutiva. Esto es, el signo o la "función sígnica" son, por naturaleza, cambiantes, tan solo detenidos, fotografiables, en su momento de significación o, dicho con los términos de Peirce, cuando crean hábitos de acción. En el proceder argumentativo de Eco, el dinamismo de los signos está presente, pues él mismo nos remitió a la concepción peirceana de la semiosis como complejo tejido de signos ilimitados en movimiento. De hecho, la expresión "semiosis ilimitada" se debe precisamente a la terminología empleada por él en su hermenéutica de las cadenas de los interpretantes a los que aludía el filósofo norteamericano. Dos cuadros de René Magritte, a los que también se refirió Foucault como ejemplos claros de similitud -según la presentada acepción-, nos podrían servir para ilustrar, a mayores, la semiosis, esto es, la vida continua de los signos, su proceder triádico.

El primero, Le deux mystères de 1966 es un cuadro con dos pipas pintadas, una más pequeña representada en el lienzo Ceci n'est pas une pipe, apoyado sobre un caballete, y una pipa más grande que ocupa el lado izquierdo de la tela, suspendida en el aire, actuando a modo de modelo de aquella, de referente de la primera pipa. Sin embargo, este referente, al que parece remitir la pipa pequeña del lienzo, tampoco sería la pipa 'real' sino tan solo otro signo, otro interpretante, al igual que las letras dibujadas, "ceci n'est pas une pipe", que figuran en el pequeño lienzo serían un interpretante más (asimismo el texto pintado como interpretante a su vez del texto). Esta idea de la meta-representación, de la representación de la representación, de un signo que nos lleva a otro, está, de igual forma, presente en el segundo cuadro; un óleo de 1962 titulado La représentation, aunque Magritte, en una carta, a André Bosmans le confesó que pensó, en un principio, en rotularlo con el revelador nombre de La fiesta continua. En 
cualquier caso, ambos títulos no parecen ser casuales ${ }^{12}$. Lo que podemos observar en él es un partido de fútbol en una verde explanada frente a un caserío y, en el margen izquierdo, la misma representación exacta en tamaño reducido. Esto es, de nuevo una representación dentro de una representación o un cuadro dentro de un cuadro ${ }^{13}$ (un cuadro que remite a un cuadro-objeto). Acaso, como dice Foucault, podríamos imaginarnos una serie de representaciones cada vez más pequeñas. También, al hilo del revelador título primigenio del cuadro, podríamos entonces imaginarnos una fiesta continua de representaciones.

Con todo, lo importante, tal y como el filósofo francés lo formula sería: “¿Qué «representa» a qué?” (Foucault, 1981: 67). A Foucault tal pregunta le sirve para insistir en que la semejanza está atada a un patrón y la similitud, expresada aquí en el lienzo de Magritte, nos situaría, por el contrario, ante una senda que, sin principio ni fin, "corre en lo sucesivo por la superficie, en un sentido siempre reversible"14 (Foucault, 1981: 67). Dicho con Peirce, estaríamos, en que ambos son, una vez más, interpretantes, signos equivalentes: "Al final, el interpretante es tan solo otro [signo] al cual se entrega la antorcha de la verdad; y en calidad de [signo] tiene a su vez su interpretante. He aquí otra serie infinita" (CP 1.339). El propio Magritte, en una entrevista publicada el 26 de diciembre de 1965, declaraba que hay un tipo de sorpresas donde también estamos inmersos en un continuum, en "la unión de algo desconocido, de algo necesario en un "reconocimiento infinito" (Magritte, 2003: 371). Tal reconocimiento ilimitado, al que nos arrastran las similitudes magritteanas, es posible porque estamos ante el quehacer de la propia semiosis.

Así, el pintor, en su reenvío de similitudes, de interpretantes como representaciones posibles del objeto extra-semiótico, mantiene vivo el sentido y la pregunta por el significado queda abierta. Es decir, el objeto

12. Cabe recordar la advertencia de la negativa de Magritte a ser interpretado. "Magritte ante el riesgo de la semiótica" fue precisamente el título escogido en el coloquio internacional sobre el pintor celebrado en Bruselas en 1998. Si bien aquí los cuadros nos sirven como pretexto para interrogarnos sobre el funcionamiento del sentido, lo cierto es que ese riesgo, de algún modo, no desaparece.

13. Uwe Schneede clasifica los cuadros de Magritte de acuerdo a los siguientes criterios: cuadros con temas detectivescos, cuadros collage, cuadros de motivación lingüística, cuadros dentro del cuadro, cuadros sobre metamorfosis y cuadros combinatorios (Schneede, 1978).

14. Esta idea de reversibilidad también la aplicó Eco a la traducción, en particular, y al proceso semiótico, en general, "uno puedo pasar del signo a su referente cuando es capaz de efectuar igualmente el camino inverso; es decir, cuando no solamente sabe que allí donde hay humo se quema algo, sino que cuando algo se quema se produce humo" (Eco, 1980: 23). 
no se agota en la representación y, en consecuencia, el signo no es una copia. En efecto, lo que ocurre es que mediante el signo nunca estaremos frente al objeto exterior al que el signo apunta, frente al objeto dinámico de Peirce, dado que éste es imposible de capturar en su totalidad, pues solamente lograremos comprenderlo desde uno o varios puntos de vista o "en algún aspecto o carácter"15 (Peirce 1.228). Esto es, tal como el signo lo representa, como objeto inmediato y, por consiguiente, nunca de una forma global. De ahí que en el reenvío de un signo a otro no se encuentre la pipa-cosa, sino tan sólo tal y como la pipa está representada, pintada.

El juego de significaciones ofrecido por el artista belga presenta así, desde mi punto de vista, de una manera clara, la acción de los propios signos. Lo cual podría leerse como una versión plástica de la "semiosis ilimitada" peirceana: "cualquier cosa que determina a otra cosa (su interpretante) a referirse a un objeto al cual ella también refiere (su objeto) de la misma manera, deviniendo el interpretante a su vez un signo y así sucesivamente ad infinitum" (Peirce 2.303). Pues "cada pensamiento es un signo que se refiere a otro signo, en un reenvío al infinito que no encuentra nunca la 'cosa' externa, si no como cosa conocida, esto es como signo de sí misma" (Fabbrichesi, 1993: 18). Es decir, el ritmo triádico de la semiosis:

Un signo, o Representamen, es un Primero que está en tal relación triádica genuina con un Segundo, llamado Objeto, como para ser capaz de determinar a un tercero, llamado su Interpretante, a asumir con su Objeto la misma relación triádica en la que él está con el mismo objeto

(Peirce 1.274).

Curiosamente, el mismo Magritte apuntó a la tríada para referirse a su propia labor de pintor: "mi tarea se asemejaba a la búsqueda de una solución para un problema en el que disponía de tres datos: el objeto, la cosa con la que había sido relacionado en la penumbra de mi conciencia $\mathrm{y}$, finalmente, la luz que me permitía ver aquella cosa" (Magritte, cit. Schneede, 1978: 83). Justamente, los tres elementos necesarios de la acción en la que algo se constituye como signo: el objeto, el representamen (la

15. El ground o fundamento del signo es justamente el concepto empleado por Peirce para aludir a esto (Peirce 1.227). 
luz, el significado que permite ver) y el interpretante (la cosa ligada a él).

\section{A MODO DE CONCLUSIÓN: VER EL SENTIDO}

El colocar imágenes de objetos reconocibles en situaciones no habituales es, como hemos visto, una característica del método magritteano que permite dejar abierto el sentido, al mismo tiempo que nos invita a interrogarnos sobre la imagen. La sensación de sorpresa y extrañeza nos exhorta a cuestionar la mirada, el modo en que miramos, a recapacitar sobre el hábito de ver pero también sobre el de leer y sobre el de pensar. Al divorciar las palabras/imágenes de las cosas, quebranta las "convenciones semióticas" y alcanza a provocar con ello una ruptura con los hábitos. Una ruptura con el código, despejando los significados usuales al situarlos en un contexto inaudito. Descontextualizando es como Magritte nos empuja a cuestionar nuestros hábitos, a re-significar, a producir nuevos significados $\mathrm{o}$, al menos, a revisar y tomar conciencia de los sentidos asociados a las cosas del mundo cotidiano. Sus imágenes como "actos de habla" destacan, con un lenguaje familiar, no ya la función imitativa o referencial del "arte de pintar" sino precisamente su carácter subversivo. Dicho con Schneede: "En sus cuadros Magritte enmascara lo cotidiano a fin de provocar un «efecto subversivo» en la conciencia" (Schneede, 1978: 113). Así, si retomamos el mencionado cuadro de La clé des songes, su título, a mi juicio, nos permitiría conectarlo precisamente con la crítica a la teoría referencialista del lenguaje, a favor del significado como uso, propuesto por Wittgenstein en las Investigaciones Filosóficas. En la subversión del orden de las asociaciones establecido por el pintor, en su disociación de las palabras/imágenes de las cosas, muestra visualmente el carácter arbitrario de los signos, su relación inmotivada y su consiguiente mutabilidad. Si, como formula el filósofo vienés, sustituimos la pregunta por el significado de las expresiones por la pregunta sobre el uso de esas expresiones, esto es, si en vez de buscar en el objeto que se representa prestamos atención al uso que se da a tal expresión-imagen, en este caso, el lenguaje de los sueños al que alude el título del cuadro, entonces la afinidad del zapato con la luna deja de ser un sinsentido, una aparente contradicción, apelando a que en los sueños se revelan asociaciones más improbables ${ }^{16}$.

16. Lo mismo ocurre en una versión anterior, titulada igualmente La llave de los sueños, de 1927, 
La idea del significado como uso, su carácter cambiante, abierto y, en definitiva, su posibilidad de resignificación, alberga una transgresión, auxiliando con ello un posible cambio de hábito. La desnaturalización a la que somete la inmutabilidad del signo, la pluralidad de sentidos que pueden ser leídos en su obra artística, impulsa una alteración semántica que conduciría a enlazar las textualidades magritteanas a la dimensión pragmática ${ }^{17}$ del lenguaje (Tordera, 1998). En este punto conviene recordar nuevamente a Peirce pues para él, el hábito, como creencia y tendencia a la acción, no es inamovible ${ }^{18}$. El "cambio de hábito", el "habit-change" que el filósofo norteamericano entendía como una modificación de las tendencias de una persona a la acción, como resultado de experiencias previas o esfuerzos, incluía la disociación o alteraciones de la asociación (Peirce 5.476). Dicho con las palabras de Umberto Eco: "En el momento en que la semiosis se ha consumado en la acción, estamos de nuevo en plena semiosis" (Eco, 1980: 165). Esto es precisamente lo que, para mi, consigue recordarnos Magritte. Su imaginación, plasmada en sus cuadros, podría ser leída como un desafío dirigido a modificar tendencias y hábitos mentales. Mediante la sorpresa, el impacto visual de sus obras que deshace ciertas relaciones y asociaciones habituales de ideas, se abre un espacio de apertura y crecimiento. El combate contra las tradicionales formas de ver y de pensar librado en las textualidades magritteanas se conectarían así con una provocación dirigida hacia el cambio de hábito, en el sentido peirceano arriba descrito. Frente a un modelo diádico del sentido, Magritte, como hemos visto, se enmarca en el ritmo triádico de las similitudes que posibilitan el crecimiento del sentido y la apertura a la novedad. Si el asemejarse mostraba lo que es visible, afirmando, por el contrario, los juegos de la similitud, disociando, no afirman sino que nos muestran lo invisible, esto es, el sentido. Pues su arte "en lugar de darle sentido a las cosas, permite ver el sentido"19 (Sampedro, 1993: 31)

pues tan solo uno de los cuatro recuadros pintados se corresponde con el nombre escrito debajo (es el caso de la esponja). El resto, al igual que ocurre con el cuadro al que me vengo refiriendo, no concuerda con la correspondencia convencional entre imágenes y palabras. En 1935, vuelve a representar el cuadro con igual inscripción, si bien en esta ocasión los nombres figuran en inglés, con lo que refuerza de nuevo la idea de la arbitrariedad del signo lingüístico. Volveríamos aquí de nuevo ante el mencionado riesgo inevitable, pues conviene recordar el rechazo del pintor al mundo de los sueños, más concretamente al psicoanálisis, como clave para interpretar sus cuadros.

17. Coincidiendo aquí con la línea dadaísta y los ready-mades de Duchamp.

18. Cabe señalar su posición falibilista respecto a su concepción de la verdad (Deladalle, 1996).

19. Corresponde matizar que Peirce distingue entre "sentido", "significado" y "significación". En 
o, expresado con Nicole Everaert-Desmedt, "la obra de Magritte es, en sí misma, una semiótica, es decir una reflexión sobre el funcionamiento de la significación" (Everaert-Desmedt, 2000: 91). En suma, Magritte nos emplaza a "ver el sentido", a captar su proceder ilimitado. Con sus juegos de similitudes plasma en imágenes justamente la construcción no lineal del sentido, mostrando de una forma plástica la dinámica de la acción de los signos presentada y teorizada por Peirce.

En conclusión, la pintura de Magritte, calificada como una forma de hacer visible lo invisible, se presenta como un lugar desde el cual re-pensar los juegos de la representación, de la percepción, de la interpretación y del funcionamiento del sentido. Las experiencias visuales, legibles en las textualidades magritteanas, producen objetos nuevos pues, sea bajo su forma icónica o verbal, en tanto signos, están en movimiento. El nacimiento que da lugar a otro signo, el proceder triádico de las similitudes entendido como un crecimiento de las interpretaciones, es el ritmo impregnado en el mundo sígnico magritteano puesto que es el fenómeno de la semiosis lo que sus obras magistralmente visibilizan.

\section{REFERENCIAS BIBLIOGRÁFICAS}

ALMANSI, G. (1981). "Prefacio". En Esto no es una pipa. Ensayo sobre Magritte, M. Foucault, 9-20. Barcelona: Anagrama.

BERGER, J. (1998). "Magritte y lo imposible". En Mirar, 89-93. Buenos Aires: Ediciones la flor. (2000). Modos de ver. Barcelona: Gustavo Gili.

CALABRESE, O. (1985). "Il problema dell'iconismo". En Il linguaggio dell'arte, 123- 144. Milano: Bompiani.

(2001). Breve storia della semiótica. Dai presocratici a Hegel. Milano: Feltrinelli.

CASETTI, F. (1980). Introducción a la semiótica. Barcelona: Fontanella. DELADALLE, G. (1996). Leer hoy a Peirce. Barcelona: Gedisa.

DE SALVADOR AGRA, S. (2016). "Semiosis en el entorno hipertextual".

su correspondencia con Lady Welby matiza y explica su comprensión de cada uno de los términos (Hardwick, 1977). 
Adversus. Revista de Semiótica, XIII.30, 66-89 (también en http://www.adversus.org/indice/nro-30/articulos/XIII3003.pdf [13/07/20178]).

ECO, U. (1977). Tratado de Semiótica General. Barcelona: Lumen.

(1980). Signo. Barcelona: Labor.

(1997). "Iconismo e Ipoicone". En Kant e l'ornitorinco, 295-349.

Milano: Bompiani.

(2009). Opera aperta. Forma e indeterminazione nelle poetiche contemporanee. Milano: Bompiani.

(2012). "Per una guerriglia semiologica". En Il costume di casa. Evidenze e misteri dell'ideologia italiana negli anni Sessanta, 409423. Milano: Bompiani.

EVERAERT-DESMEDT, N. (2000). "Acercamiento semiótico a la obra de Magritte”. En Ver y leer a Magritte, B. Fernández Taviel (coord.), 91-107. Ciudad Real: Ediciones de la Universidad de Castilla-La Mancha.

FABBRICHESI L. R. (1993). Introduzione a Peirce. Roma-Bari: Laterza. FERNÁNDEZ TAVIEL DE ANDRADE, B. (coord.) (2000). Ver y leer a Magritte. Ciudad Real: Ediciones de la Universidad de Castilla-La Mancha.

FOUCAULT, M. (1981). Esto no es una pipa. Ensayo sobre Magritte. Barcelona: Anagrama.

HARDWICK, Ch. (1977). Semiotic and Significs. The Correspondence between Charles S. Peirce and Victoria Lady Welby. Bloomington: Indiana University Press.

KONERSMANN, R. (1996). René Magritte. La reproducción prohibida. Sobre la visibilidad del pensamiento. Madrid: Siglo XXI Editores.

LLEDÓ, E. (1991). El silencio de la escritura. Madrid: Centros de Estudios Constitucionales.

MAGRITTE, R. (2003). Escritos. Madrid: Editorial Síntesis.

MALDONADO, T. (2007) “Appunti sull'iconicità". En Reale e Virtuale, 119-145. Milano: Feltrinelli.

MORRIS, Ch. (1985). Fundamentación de la teoría de los signos. Barcelona: Paidós.

PAQUET, M. (2000). René Magritte (1898-1967) El pensamiento visible. Madrid: Taschen.

PANCORBO, L. (1977). Ecoloquio con Umberto Eco o la magia imposible 
de la semiótica. Barcelona: Anagrama.

PLATÓN (1987). Crátilo. Madrid: Gredos.

PEIRCE, Ch. S. (1931-1958). Collected Papers. Cambridge: Harvard University Press.

(1974). La ciencia de la semiótica. Buenos Aires: Ediciones Nueva Visión.

RÉCANATI, F. (1981). La transparencia y la enunciación. Introducción a la Pragmática. Buenos Aires: Hachette.

SAMPEDRO, F.; GONZÁLEZ-ALEGRE, A. y ÁLVARES, X. M. a (1993). Magritte $X$ 3. Vigo: Laiovento.

SCHNEEDE, U. M. (1978). René Magritte. Madrid: Labor.

TORCZYNER, H. (1978). Magritte. Signos e imágenes. Barcelona: Blumen .

TORDERA, A. (1978). Hacia una semiótica pragmática. El signo en Ch. S. Peirce. Valencia: Fernando Torres Editor.

WITTGENSTEIN, L. (1988). Investigaciones filosóficas. Barcelona: Crítica.

Recibido el 9 de abril de 2017.

Aceptado el 6 de junio de 2017. 